\title{
Suppression of Taxanes Cytotoxicity by Citrus Flavonoid Hesperetin in PPC-1 Human Prostate Cancer Cells
}

\author{
KATRIN SAK ${ }^{1}$, HELEN LUST ${ }^{1}$, MARJU KASE ${ }^{2,3}$, MARIKA SAAR $^{4}$ and JANA JAAL ${ }^{1,2}$ \\ ${ }^{I}$ Clinic of Hematology and Oncology, Institute of Clinical Medicine, University of Tartu, Tartu, Estonia; \\ ${ }^{2}$ Department of Radiotherapy and Oncological Therapy, Tartu University Hospital, Tartu, Estonia; \\ ${ }^{3}$ East-Tallinn Central Hospital, Tartu, Estonia; \\ ${ }^{4}$ Pharmacy, Tartu University Hospital, Tartu, Estonia
}

\begin{abstract}
Background/Aim: More than half of prostate cancer patients use, in addition to conventional therapies, some kind of complementary medicine, including flavonoidrich products. However, knowledge about the co-effects of flavonoids with cytotoxic chemotherapies is still rather poor. Therefore, this study was undertaken to assess the cytotoxic activity of flavonoids and their interactions with taxanes in human advanced prostate cancer cells. Materials and Methods: Cytotoxicity of different flavonoids and their effects on the efficacy of docetaxel and cabazitaxel were studied in the human metastatic prostate cancer cell line PPC-1, using MTT colorimetric assay. Results: Both taxanes suppressed the viability of PPC-1 cells with $I C_{50}$ values in the nanomolar range. Tested flavonoids exerted cytotoxic activity only at high micromolar concentrations or revealed no remarkable effect on cell survival. Simultaneous treatment of cells with taxanes and flavonoids baicalein, chrysin, luteolin, fisetin, quercetin, genistein or daidzein did not lead to any change in chemotherapy-induced cytotoxicity. However, simultaneous exposure of cells to hesperetin and taxanes resulted in 9.8- and 13.1-fold reduction in cytotoxicity of docetaxel and cabazitaxel, respectively. Conclusion: Flavonoid hesperetin remarkably suppressed the cytotoxic efficacy of taxanes in prostate cancer cells. Therefore, caution is required from prostate cancer patients who take hesperetin-containing oral supplements.
\end{abstract}

Prostate cancer is the most common malignancy among men worldwide. According to GLOBOCAN, about 1.1 million new cases and 307,000 deaths were recorded in 2012,

Correspondence to: Katrin Sak, Clinic of Hematology and Oncology, University of Tartu, L. Puusepa 8, 51014 Tartu, Estonia. Tel: +372 53341381,e-mail: katrin.sak@ut.ee

Key Words: Metastatic prostate cancer, flavonoids, hesperetin, docetaxel, cabazitaxel. making it thus the third-leading cause of cancer-related death in men $(1,2)$. Although treatment with radiation and surgery can be curative in localized organ-confined prostate tumors, more than one third of patients progress to metastatic disease $(3,4)$. For these men, androgen deprivation therapy is the standard of care (3). However, after initial remission in most patients, tumor eventually develops into castration-resistant disease (5). Chemotherapy with taxane (docetaxel or cabazitaxel) is currently considered one of the effective treatment options for advanced castration-resistant prostate cancer that exerts its anti-tumor activity through direct antimitotic effects as well as by suppressing the microtubuledependent trafficking of proteins like androgen receptors (6). Despite effective anti-cancer therapies, more than half of prostate cancer patients use additionally some kind of complementary medicines (CM), whereas the majority of patients believe that CM are "helpful" or "very helpful" for their condition (7). This is somewhat surprising since conclusive evidence regarding the use of CM is still lacking and current knowledge relies mostly on few experimental studies performed with cancer cell lines and/or animal models. Furthermore, interactions of CM with conventional anti-cancer therapies, including taxane-based chemotherapy in prostate cancer, are largely unknown.

Previous studies have reported that the most commonly used $\mathrm{CM}$ among cancer patients are vitamins and different herbal products $(8,9)$. Among those, interest has been lately focused to plant secondary metabolites, flavonoids, which can be found abundantly in fruits and vegetables, seeds and herbs. Based on their structural peculiarities, flavonoids can be divided into six subclasses: flavonols, flavones, flavanones, flavanols or catechins, isoflavones and anthocyanidins. The most wellknown flavonols are quercetin and fisetin; flavones include luteolin, chrysin and baicalein; hesperetin belongs to the flavanones subclass; and genistein and daidzein are recognized as isoflavones (10). Numerous experimental studies have shown that these natural polyphenols exhibit various beneficial anti-cancer properties, such as antioxidant, anti-inflammatory, 
antiproliferative, pro-apoptotic, antiangiogenic as well as antimetastatic effects (10). However, the current knowledge about co-effects of flavonoids with cytotoxic chemotherapy is still rather poor. Therefore, the aim of this study was to thoroughly assess the cytotoxic activity of different flavonoids and their interactions with chemotherapeutics docetaxel and cabazitaxel in the human metastatic prostate cancer cell line PPC-1.

\section{Materials and Methods}

Cell line and flavonoids. In the current work, the cytotoxic activity of flavonoids and their effects on the efficacy of docetaxel and cabazitaxel in human metastatic prostate cancer cell line PPC-1 were studied. In experimental models, this cell line has been shown to be tumorigenic and highly metastatic, resembling the clinical situation of metastatic prostate cancer with visceral metastases requiring taxane-based systemic chemotherapy (11). Structures of the studied flavonoids are presented in Figure 1.

Chemicals. All flavonoids (baicalein, chrysin, fisetin, hesperetin, luteolin, quercetin, genistein and daidzein) were purchased from Santa Cruz Biotechnology (Dallas, TX, USA). 3-(4,5-dimethylthiazol-2-yl)2,5-diphenyltetrazolium bromide (MTT) and L-glutamine were the products of Sigma-Aldrich (St. Louis, MO, USA). Dimethyl sulfoxide (DMSO) was from Mediatech, Inc (Manassas, VA, USA). Phosphate buffered saline (PBS) was obtained from Lonza (Verviers, Belgium). The chemotherapeutics, docetaxel (Accord, London, UK) and cabazitaxel (Sanofi-Aventis, Paris, France) were used.

Cell culture conditions. PPC-1 human prostate cancer cells were cultivated in Dulbecco's Modified Eagle's Medium (DMEM) (Life Technologies Corporation, Grand Island, NY, USA) supplemented with $10 \%$ of heat-inactivated fetal bovine serum (FBS) (Invitrogen $^{\mathrm{TM}}$, Auckland, NZ, USA). Cells were maintained in an incubator at $37^{\circ} \mathrm{C}$ with $5 \% \mathrm{CO}_{2}$ and passaged 2-3 times per week.

Measurement of cell viability by MTT assay. The cytotoxic activities of taxanes and flavonoids in PPC-1 cells were tested by the MTT colorimetric assay, first described by Mosmann in 1983 (12). In detail, the cells were plated on to 96-well U-shaped bottom plates at a concentration of $1 \times 10^{5}$ cells $/ \mathrm{ml}$ of medium, as a $100 \mu \mathrm{l}$ of suspension. Cells were counted in a Bürker counting chamber. As phenol red can interfere with the reading of absorbance (13), the cells were seeded in phenol red-free RPMI-1640 medium (Mediatech, Inc, Manassas, VA, USA). After overnight incubation, cells were treated with varying doses of taxanes $(0.01 \mathrm{nM}-100 \mathrm{nM})$, flavonoids $(10 \mathrm{nM}-500 \mu \mathrm{M})$ or different combinations of taxanes and flavonoids for $48 \mathrm{~h}$ at $37^{\circ} \mathrm{C}$ and $5 \% \mathrm{CO}_{2}$. At the end of the incubation, $50 \mu \mathrm{l}$ of MTT solution in PBS was added to the wells in a final concentration of MTT of $5 \mathrm{mg} / \mathrm{ml}$. Plates were further incubated for $4 \mathrm{~h}$ followed by centrifugation at $1,000 \mathrm{rpm}$ for $10 \mathrm{~min}$ and removal of the supernatant. To dissolve the purple formazan crystals $150 \mu \mathrm{l}$ of DMSO was added and the plates were shaken for $30 \mathrm{~min}$. Absorbance was measured at $540 \mathrm{~nm}$ using a LED based microplate reader (Ledetect 96, Labexim Products, Austria). To calculate the proportion of surviving cells, the following formula was used: (OD of drug-treated sample - OD of blank)/(OD of control OD of blank) $\times 100 \%$, where OD of blank represents the absorbance reading of wells containing the buffer only (without cells) and OD of control represents the reading value of wells without any added test compounds. Dose-response curves were constructed to evaluate the half-maximal inhibitory concentrations ( $\mathrm{IC}_{50}$ values). All experiments were performed in triplicates.

Statistics. Data were analyzed using the GraphPad Prism statistical software. Kolmogorov-Smirnov test for normality was performed to evaluate if the data were in normal distribution. The one-way analysis of variance (ANOVA) was applied to determine whether there were any significant differences between the means. $p$-Values less than 0.05 were considered as statistically significant and all values were expressed as mean \pm standard deviation (SD).

\section{Results}

Cytotoxic profiles of taxanes and flavonoids in PPC-1 human prostate cancer cells. Both taxanes, docetaxel and cabazitaxel, suppressed the viability of PPC-1 cells with the half-maximal inhibitory constants $\left(\mathrm{IC}_{50}\right)$ of $1.7 \pm 0.6 \mathrm{nM}$ for docetaxel and $0.5 \pm 0.2 \mathrm{nM}$ for cabazitaxel (Figure 2a, Table I). Tested flavonoids exerted cytotoxic activity only at high micromolar concentrations with $\mathrm{IC}_{50}$ values of $78.5 \pm 1.3 \mu \mathrm{M}$ for quercetin, $80.2 \pm 1.5 \mu \mathrm{M}$ for fisetin, $83.6 \pm 1.4 \mu \mathrm{M}$ for luteolin and $103.8 \pm 1.4 \mu \mathrm{M}$ for baicalein, or revealed no remarkable effect on cell survival with concentrations up to $100 \mu \mathrm{M}$ (chrysin, hesperetin, genistein, daidzein) (Figure 2b, Table I).

Effect of flavonoids on cytotoxicity of docetaxel and cabazitaxel in PPC-1 human prostate cancer cells. Simultaneous treatment of PPC-1 cells with taxanes and flavonoids (baicalein, chrysin, luteolin, fisetin, quercetin, genistein or daidzein) at $10 \mu \mathrm{M}$ concentration did not lead to any shift in the dose response curves of docetaxel or cabazitaxel showing no potentiating or suppressive effect of these plant secondary metabolites (data not shown).

Simultaneously added hesperetin decreases cytotoxicity of docetaxel and cabazitaxel in PPC-1 human prostate cancer cells. In contrast to all other tested flavonoids, simultaneous exposure of cells to $10 \mu \mathrm{M}$ hesperetin and taxanes resulted in about three-fold decrease in cytotoxic, i.e. three-fold increase in $\mathrm{IC}_{50}$ values, of both chemotherapeutics. Moreover, $30 \mu \mathrm{M}$ of hesperetin resulted in 9.8- and 13.1-fold reduction in the cytotoxicity of docetaxel and cabazitaxel, respectively (Figure $3 \mathrm{a}$ and $3 \mathrm{~b}$, Table II). When cells were cotreated with cabazitaxel and $30 \mu \mathrm{M}$ hesperetin, this inhibitory effect reached statistical significance $(p=0.04)$ (Table II).

Hesperetin did not interfere with taxane-induced cytotoxicity in PPC-1 cells when added $24 \mathrm{~h}$ after taxane treatment. If $30 \mu \mathrm{M}$ hesperetin were added $24 \mathrm{~h}$ after treatment of cells with docetaxel or cabazitaxel, no suppressive effect of this citrus flavonoid on taxanes cytotoxicity was observed (Figure $4 \mathrm{a}$ and $4 \mathrm{~b}$ ). 


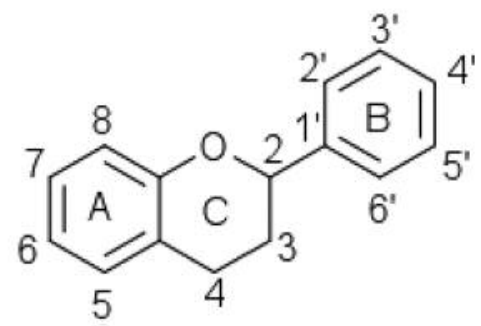

\section{General skeleton of flavonoids}<smiles>O=c1cc(-c2ccc(O)c(O)c2)oc2cc(O)cc(O)c12</smiles>

\section{Luteolin}<smiles>O=c1cc(-c2ccccc2)oc2cc(O)c(O)c(O)c12</smiles>

\section{Baicalein}<smiles>O=c1c(O)c(-c2ccc(O)c(O)c2)oc2cc(O)ccc12</smiles>

Fisetin<smiles>O=c1c(-c2ccc(O)cc2)coc2cc(O)cc(O)c12</smiles>

Genistein<smiles>O=c1cc(-c2ccccc2)oc2cc(O)cc(O)c12</smiles>

Chrysin<smiles>COc1ccc([C@H]2CC(=O)c3c(O)cc(O)cc3O2)cc1O</smiles>

Hesperetin<smiles>O=c1c(O)c(-c2ccc(O)c(O)c2)oc2cc(O)cc(O)c12</smiles>

Quercetin<smiles>O=c1c(-c2ccc(O)cc2)coc2cc(O)ccc12</smiles>

Daidzein

Figure 1. Chemical structures of tested flavonoids. 

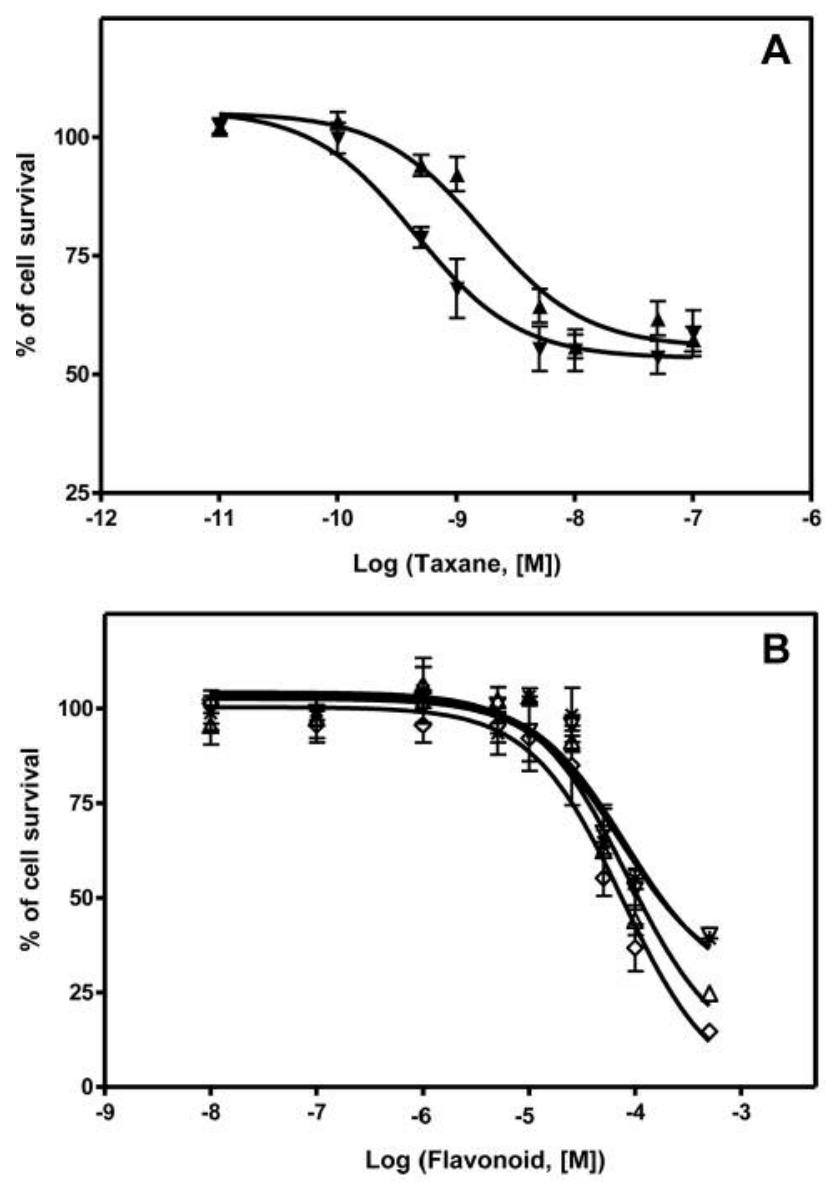

Figure 2. Cell growth inhibitory effects of taxanes (docetaxel $\boldsymbol{\Lambda}$, cabazitaxel $\mathbf{\nabla} ; A)$ and cytotoxically active flavonoids (luteolin $\triangle$, baicalein $\nabla$, quercetin $\diamond$, fisetin $* ; B)$ in PPC-1 human prostate cancer cells by treating the cells with respective compounds for $48 \mathrm{~h}$.

\section{Discussion}

More than half of prostate cancer patients use additionally some kind of $\mathrm{CM}$ product during the course of active anticancer therapy. However, interactions of $\mathrm{CM}$ with conventional anticancer therapies, including taxane-based chemotherapy, are largely unknown. Therefore, we assessed the cytotoxic activity of different flavonoids and their interactions with the chemotherapeutics docetaxel and cabazitaxel in human metastatic prostate cancer cell line PPC-1.

Both taxanes, docetaxel and cabazitaxel, significantly decreased the viability of PPC-1 cells as measured by MTT assay. Sensitivity to docetaxel has been described earlier (14); however, no study was identified on the cytotoxic effect of cabazitaxel in PPC-1 cell line was identified. Next to taxanes, the cytotoxic profile of the number of commercially available flavonoids was examined. Our study showed that some flavonoids exerted cytotoxic activity only at high micromolar
Table I. IC 50 values of taxanes and flavonoids in PPC-1 human prostate cancer cells following $48 \mathrm{~h}$ of treatment (data are expressed as mean values \pm standard deviation $(S D)$ ).

\begin{tabular}{lc}
\hline Chemotherapeutics & $\mathrm{IC}_{50}, \mathrm{nM}$ \\
\hline Taxanes & \\
Docetaxel & $1.7 \pm 0.6$ \\
Cabazitaxel & $0.5 \pm 0.2$ \\
\hline Flavonoids & $\mathrm{IC}_{50}, \mu \mathrm{M}$ \\
\hline Flavones & \\
Baicalein & $103.8 \pm 1.4$ \\
Chrysin & $197.2 \pm 1.4$ \\
Luteolin & $83.6 \pm 1.4$ \\
Flavanones & \\
Hesperetin & $268.5 \pm 1.6$ \\
Flavonols & \\
Fisetin & $80.2 \pm 1.5$ \\
Quercetin & $78.5 \pm 1.3$ \\
Isoflavones & \\
Genistein & $>>100$ \\
Daidzein & $>>100$ \\
\hline
\end{tabular}

Table II. Antagonistic effect of $10 \mu M$ and $30 \mu M$ hesperetin on docetaxel or cabazitaxel cytotoxicity in PPC-1 human prostate cancer cells by combined treatment of cells for $48 \mathrm{~h}$. Statistically significant difference $(p<0.05)$ is marked with an asterisk.

\begin{tabular}{lcc}
\hline & $\begin{array}{c}\text { Ratio of } \mathrm{IC}_{50} \text { for taxane } \\
\text { in the presence } \\
\text { of hesperetin and } \\
\mathrm{IC}_{50} \text { for taxane alone }\end{array}$ & $p$-Value \\
\hline Docetaxel & 1.0 & \\
$+10 \mu \mathrm{M}$ hesperetin & 3.0 & 0.62 \\
$+30 \mu \mathrm{M}$ hesperetin & 9.8 & 0.13 \\
Cabazitaxel & 1.0 & 0.56 \\
$+10 \mu \mathrm{M}$ hesperetin & 2.8 & $0.04^{*}$ \\
$+30 \mu \mathrm{M}$ hesperetin & 13.1 & \\
\hline
\end{tabular}

concentrations (quercetin, fisetin, luteolin, baicalein) while other flavonoids had no significant effect on cell survival (chrysin, hesperetin, genistein, daidzein). Although similar cytotoxic effects have been seen in PPC-1 cell line for quercetin, there are no reports describing the effects of the other tested flavonoids (15). Few studies have described the cytotoxic actions of flavonoids such as luteolin, genistein and chrysin but using other prostate cancer cell lines (e.g., LNCaP, PC3, DU145) (16-20).

To further characterize the effects of flavonoids, their combinations with the chemotherapeutics docetaxel or cabazitaxel were investigated. Simultaneous treatment of 

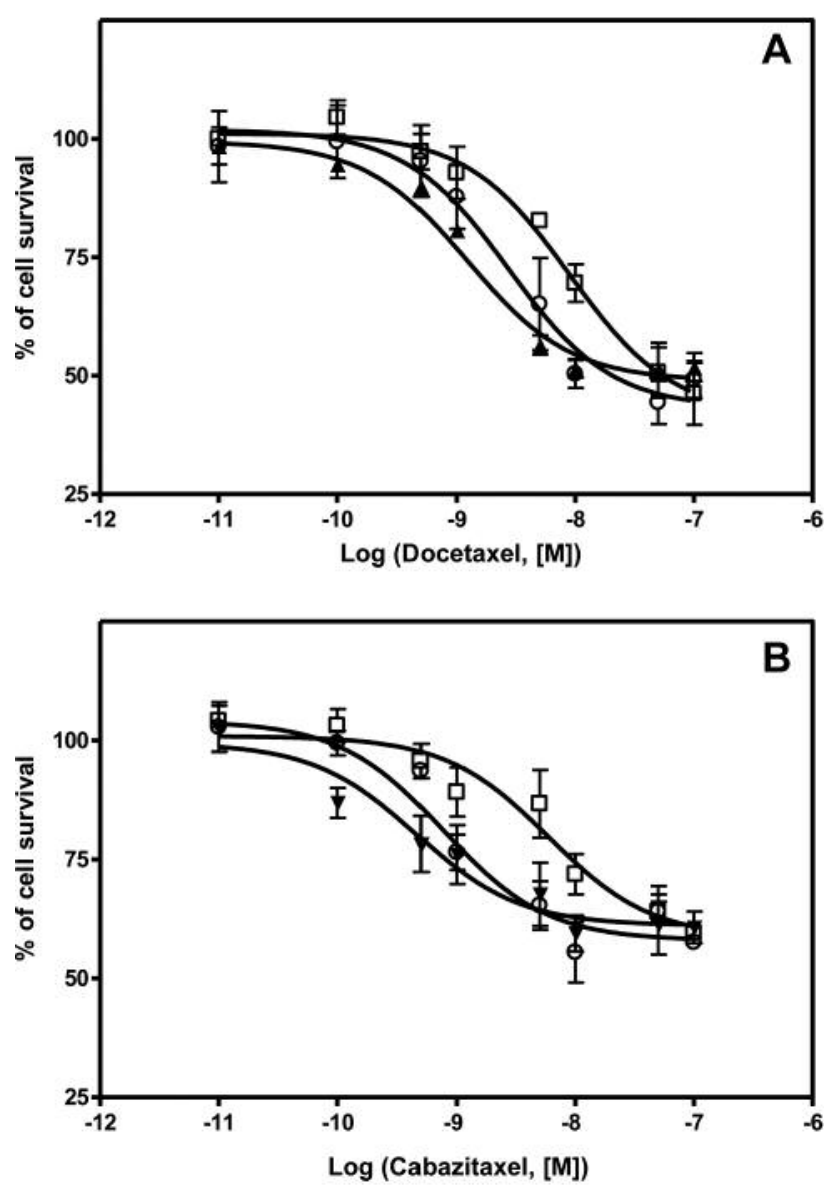

Figure 3. Suppression of docetaxel $(\mathbf{\Lambda}, A)$ and cabazitaxel $(\boldsymbol{\nabla}, B)$ cytotoxicity by $10 \mu \mathrm{M}(\bigcirc)$ and $30 \mu M(\square)$ hesperetin in PPC-1 human prostate cancer cells by treating the cells with flavonoids and taxanes simultaneously for $48 \mathrm{~h}$.

PPC-1 cells with taxanes and flavonoids (baicalein, chrysin, luteolin, fisetin, quercetin, genistein or daidzein) did not lead to any shift in the dose response curves of docetaxel or cabazitaxel showing no potentiating or suppressive effect of these plant secondary metabolites. This is in contrast to other prostate cancer cell lines where a potentiating effect of some flavonoids on taxane cytotoxicity has been reported. For example, in the case of human prostate cancer cells $22 \mathrm{Rv} 1, \mathrm{PC}-$ $3 \mathrm{M}-$ luc-6 or C4-2, the flavonol fisetin was shown to enhance the cytotoxic effects of cabazitaxel (21). Similar sensitization of $\mathrm{PC}-3, \mathrm{C} 4-2$ or $\mathrm{ARCaP}_{\mathrm{M}}$ cells to cabazitaxel response was observed also in combination with the isoflavone genistein (22). Moreover, the therapeutic efficacy of docetaxel was enhanced by the presence of quercetin in PC-3-engineered xenograft prostate tumors (23). These differences suggest that the behavior of flavonoids largely depends on their structure as well as the specific features of prostate cancer cell line, probably including their distinct hormone and taxane sensitivity.
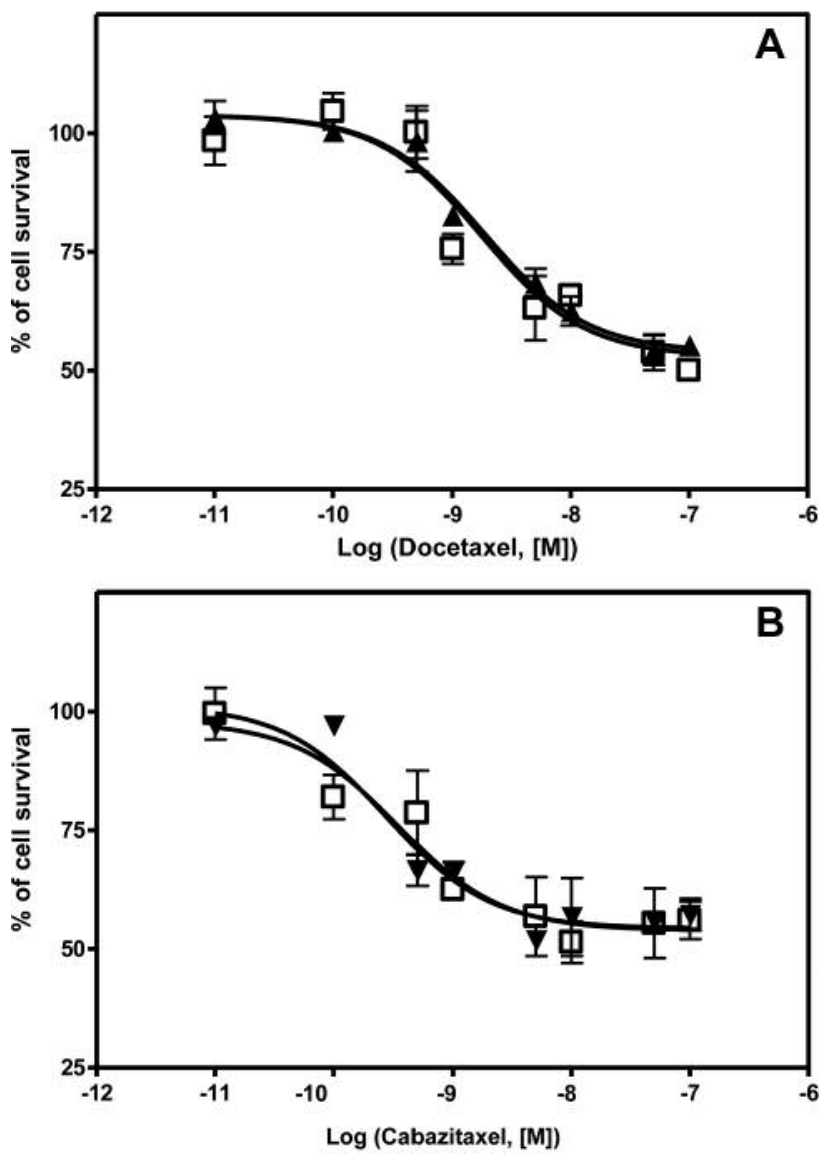

Figure 4. Treatment of PPC-1 human prostate cancer cells pretreated with docetaxel $(\mathbf{\Lambda}, A)$ or cabazitaxel $(\boldsymbol{\nabla}, B)$ for $24 h$ with $30 \mu M$ hesperetin $(\square)$ had no effect on taxane-induced cytotoxicity.

The most important finding of this study was that one of the tested flavonoids - citrus flavanone hesperetin - decreased the effect of taxanes. Both docetaxel and especially cabazitaxel cytotoxicity was markedly reduced by simultaneous addition of hesperetin to culture media. Interestingly, this inhibitory effect of hesperetin was only seen upon simultaneous treatment with taxane and not when prostate cancer cells were treated with the flavonoid $24 \mathrm{~h}$ after treatment with the chemotherapeutic and flavonoid administration, showing that only concomitant co-effects are important.

It has been previously shown that flavonoids may participate in different intermolecular and intercellular interactions. Flavonoids are able to penetrate into biological membranes, particularly in compartments known as lipid rafts. By influencing physical properties of the lipid bilayer, flavonoids may control the arrangement of membrane proteins and the formation of functional complexes responsible for cellular signal transduction and the regulation 
of the metabolism (24). For example, it has been reported that hesperetin improves antioxidant status and membrane lipid compositions in rat liver (25). Moreover, in Caco-2 intestinal epithelial cell monolayers, hesperetin has been shown to increase transepithelial electrical resistance and the expression of tight junction proteins such as occludin and claudins 1, 3 and 4 (26). The latter shows that hesperetin influences cell membrane barrier integrity and therefore it is rather plausible that by increasing the expression of tight junction proteins, it may affect entry of chemotherapeutics into the cancer cells and thereby reduce the cytotoxic effects of anti-cancer therapy.

There are only few studies that have examined anticancer treatment combinations with hesperetin. In an in vivo study in rats, oral administration of hesperetin in combination with doxorubicin suppressed the expression of some apoptosis-associated genes, such as NF- $\mathrm{kB}, \mathrm{p} 38$ and caspase-3 (27). However, in combination with hormonal therapy (bicalutamide), hesperetin has been shown to potentiate apoptotic effects of cancer therapy in taxaneresistant PC-3 prostate cancer cells (28), pointing again toward the possibility that the effect of flavonoids on prostate cancer cells may be different in castration- and taxane- sensitive and castration- and taxane-resistant clinical situations.

Although the action of natural products in cancer patients can be rather different from experimental laboratory systems due to side-effects and safety (29), but also bioavailability, i.e., intestinal absorption, metabolic conversion and excretion of these compounds from the human body (30), there is no doubt that caution is needed when consuming plant-derived hesperetin supplements during the active taxane-based chemotherapy of advanced prostate cancer. Also, caution is needed in all dietary recommendations, since hesperetin can be found abundantly in various citrus fruits, such as oranges, mandarins, tangerines, limes, lemons, pomelos and grapefruits $(30,31)$. Additionally, it is important to know that another important source of this flavanone includes the herb peppermint (30).

\section{Conclusion}

Our study showed that dietary flavonoid hesperetin remarkably decreased the cytotoxic effect of chemotherapeutics docetaxel and especially cabazitaxel in prostate cancer cells. Therefore, caution is clearly needed for prostate cancer patients who take oral supplements containing hesperetin or follow special diets rich in citrus fruits and peppermint.

\section{Conflicts of Interest}

The Authors declare that there is no conflict of interest regarding the publication of this paper.

\section{Acknowledgements}

This work was supported by the Estonian Society of Clinical Oncologists and by the research grant from Tartu University Hospital, Estonia.

\section{References}

1 Bashir MN: Epidemiology of prostate cancer. Asian Pac J Cancer Prev 16: 5137-5141, 2015.

2 Litwin MS and Tan HJ: The diagnosis and treatment of prostate cancer: A Review. JAMA 317: 2532-2542, 2017.

3 Fakhrejahani F, Madan RA and Dahut WL: Management options for biochemically recurrent prostate cancer. Curr Treat Options Oncol 18: 26, 2017.

4 Norum J and Nieder C: Treatments for metastatic prostate cancer (mPC): A review of costing evidence. Pharmacoeconomics 35: 1223-1236, 2017.

5 Handy CE and Antonarakis ES: Sequencing treatment for castration-resistant prostate cancer. Curr Treat Options Oncol 17: 64, 2016.

6 Diamond E, Garcias Mdel C, Karir B and Tagawa ST: The evolving role of cytotoxic chemotherapy in the management of patients with metastatic prostate cancer. Curr Treat Options Oncol 16: 9, 2015.

7 McDermott CL, Blough DK, Fedorenko CR, Arora NK, Zeliadt SB, Fairweather ME, Oakley-Girvan I, Van Den Eeden SK and Ramsey SD: Complementary and alternative medicine use among newly diagnosed prostate cancer patients. Support Care Cancer 20: 65-73, 2012.

8 Klempner SJ and Bubley G: Complementary and alternative medicines in prostate cancer: from bench to bedside? Oncologist 17: 830-837, 2012.

9 Pihlak R, Liivand R, Trelin O, Neissar H, Peterson I, Kivistik S, Lilo $\mathrm{K}$ and Jaal J: Complementary medicine use among cancer patients receiving radiotherapy and chemotherapy: methods, sources of information and the need for counselling. Eur $\mathrm{J}$ Cancer Care (Engl) 23: 249-254, 2014.

10 Sak K: Cytotoxicity of dietary flavonoids on different human cancer types. Pharmacogn Rev 8: 122-146, 2014.

11 Brothman AR, Wilkins PC, Sales EW and Somers KD: Metastatic properties of the human prostatic cell line, PPC-1, in athymic nude mice. J Urol 145: 1088-1091, 1991.

12 Mosmann T: Rapid colorimetric assay for cellular growth and survival: application to proliferation and cytotoxicity assays. J Immunol Methods 65: 55-63, 1983.

13 Kupcsik L: Estimation of cell number based on metabolic activity: the MTT reduction assay. Methods Mol Biol 740: 13-19, 2011.

14 Akhavan A, McHugh KH, Guruli G, Bies RR, Zamboni WC, Strychor SA, Nelson JB and Pflug BR: Endothelin receptor A blockade enhances taxane effects in prostate cancer. Neoplasia 8: 725-732, 2006.

15 Samuel T, Fadlalla K, Turner $\mathrm{T}$ and Yehualaeshet TE: The flavonoid quercetin transiently inhibits the activity of taxol and nocodazole through interference with the cell cycle. Nutr Cancer 62: 1025-1035, 2010.

16 Markaverich B and Alejandro M: Bioflavonoids, type II (H3)estradiol binding sites and prostatic cancer cell proliferation. Int J Oncol 11: 1311-1319, 1997. 
17 Chiu FL and Lin JK: Downregulation of androgen receptor expression by luteolin causes inhibition of cell proliferation and induction of apoptosis in human prostate cancer cells and xenografts. Prostate 68: 61-71, 2008.

18 Fang J, Zhou Q, Shi XL and Jiang BH: Luteolin inhibits insulinlike growth factor 1 receptor signaling in prostate cancer cells. Carcinogenesis 28: 713-723, 2007.

19 Knowles LM, Zigrossi DA, Tauber RA, Hightower C and Milner JA: Flavonoids suppress androgen-independent human prostate tumor proliferation. Nutr Cancer 38: 116-122, 2000.

20 Parajuli P, Joshee N, Rimando AM, Mittal S and Yadav AK: In vitro antitumor mechanisms of various Scutellaria extracts and constituent flavonoids. Planta Med 75: 41-48, 2009.

21 Mukhtar E, Adhami VM, Siddiqui IA, Verma AK and Mukhtar H: Fisetin Enhances Chemotherapeutic Effect of Cabazitaxel against Human Prostate Cancer Cells. Mol Cancer Ther 15: 2863-2874, 2016.

22 Zhang S, Wang Y, Chen Z, Kim S, Iqbal S, Chi A, Ritenour C, Wang YA, Kucuk O and Wu D: Genistein enhances the efficacy of cabazitaxel chemotherapy in metastatic castration-resistant prostate cancer cells. Prostate 73: 1681-1689, 2013.

23 Wang P, Henning SM, Magyar CE, Elshimali Y, Heber D and Vadgama JV: Green tea and quercetin sensitize PC-3 xenograft prostate tumors to docetaxel chemotherapy. J Exp Clin Cancer Res 35: 73, 2016.

24 Tarahovsky YS, Kim YA, Yagolnik EA and Muzafarov EN: Flavonoid-membrane interactions: involvement of flavonoidmetal complexes in raft signaling. Biochim Biophys Acta 1838: 1235-1246, 2014.
25 Miler M, Zivanovic J, Ajdzanovic V, Orescanin-Dusic Z, Milenkovic D, Konic-Ristic A, Blagovievic D, Milosevic V and Sosic-Jurjevic B: Citrus flavanones naringenin and hesperetin improve antioxidant status and membrane lipid compositions in the liver of old-aged Wistar rats. Exp Gerontol 84: 49-60, 2016.

26 Noda S, Tanabe S and Suzuki T: Differential effects of flavonoids on barrier integrity in human intestinal Caco-2 cells. J Agric Food Chem 60: 4628-4633, 2012.

27 Iranshahi M, Rezaee R, Parhiz H, Roohbakhsh A and Soltani F: Protective effects of flavonoids against microbes and toxins: The cases of hesperidin and hesperetin. Life Sci 137: 125-132, 2015.

28 Arya A, Khandelwal K, Ahmad H, Laxman TS, Sharma K, Mittapelly N, Agrawal S, Bhatta RS and Dwivedi AK: Codelivery of hesperetin enhanced bicalutamide induced apoptosis by exploiting mitochondrial membrane potential via polymeric nanoparticles in a PC-3 cell line. RSC Adv 6: 5925-5935, 2016.

29 Werneke U, Earl J, Seydel C, Horn O, Crichton P and Fannon D: Potential health risks of complementary alternative medicines in cancer patients. Br J Cancer 90: 408-413, 2004.

$30 \mathrm{Sak} \mathrm{K}$ : Intake of individual flavonoids and risk of carcinogenesis: Overview of epidemiological evidence. Nutr Cancer 69: 1119-1150, 2017.

31 Somerset SM and Johannot L: Dietary flavonoid sources in Australian adults. Nutr Cancer 60: 442-449, 2008.

Received September 30, 2018

Revised October 9, 2018

Accepted October 11, 2018 